\title{
- Mental Foramen and Mandibular Canal in Dry Human Mandibles: A Cross-Sectional Morphometric Analysis \\ Section: Healthcare
}

ISI Impact Factor (2019-20): 1.628

IC Value (2019): 90.81 SJIF (2020) $=7.893$

\section{Pandey M'1 ${ }^{1}$ Rani A2 , Bajpai PK ${ }^{3}$}

'Demonstrator, Department of Anatomy, UPUMS, Saifai, Etawah, UP, India; 'Professor, Department of Anatomy, King Georges' Medical University, Lucknow, UP, India; ' 2 Lecturer, Department of Community Medicine, UPUMS, Saifai, Etawah, UP, India.

(c) (i) (3)

Copyright@IJCRR

\section{ABSTRACT}

Introduction: The mandibular foramen portrays a cardinal anatomical landmark for the repositioning of the mandible during sagittal split osteotomies performed to correct structural deformities like prognathism and retrognathia. These landmarks are crucial for adequate anaesthesia while performing the inferior alveolar nerve block. The mental foramen is an important landmark in carrying out invasive procedures like a mental or incisive nerve block.

Objectives: To observe the shape, position and distance from various mandibular anatomical landmarks of the mental foramen, and the length of the mandibular canal.

Methods: This cross-sectional study included 41 human mandibles, which were available in the department. After applying the inclusion and exclusion criteria, thirty dried adult human mandibles with an intact alveolar margin of unknown gender were used.

Results: The shape of mental foramen was found oval in 80 per cent and circular in 20 per cent of the mandible irrespective of side. The mean distance of mental foramen from symphysis menti, posterior border of the ramus, alveolar crest, and lower border of the body of mandible was found $24.38 \pm 1.91 \mathrm{~mm}, 63.62 \pm 2.5 \mathrm{~mm}, 13.15 \pm 1.64 \mathrm{~mm}$, and $14.15 \pm 1.58 \mathrm{~mm}$ on the right side. Whereas on the left side mean distance was $24.01 \pm 1.86 \mathrm{~mm}, 63.49 \pm 2.22 \mathrm{~mm}, 13.23 \pm 1.65 \mathrm{~mm}$, and $14.06 \pm 1.69 \mathrm{~mm}$, respectively, from the above parameters.

Conclusions: Mental foramen's usual position was below the second premolar. Since it is not possible to palpate the MF clinically, it is necessary to know its accurate place. This will reduce the chances of inadvertent injury during invasive dental procedures like various pre-prosthetic operations and implant insertion.

Key Words: Human Mandibles, Mental Foramen, Mandibular Canal, Morphometric Analysis, Nerve block

\section{INTRODUCTION}

The mandible is the strongest bone of the skull and movable bone of the viscerocranium other than the ear ossicles. It bears sockets for the lower teeth and provides attachment to muscles of mastication and facial expression. ${ }^{1}$ The Meckel's cartilage arising from the first pharyngeal arch or the mandibular arch forms framework of the mandible. The gross anatomy of the mandible is composed of two parts: the body and the ramus. The body lies in a horizontal plane, and its superior border consists of sockets for upper teeth. The two vertical bony part is known as rami. The mandible's body and ramus unite at an angle that varies with age and shows sexual dimorphism in a population. The superior aspect of each ramus has coronoid and condylar processes that articulate with the temporal bone to form the temporomandibular joint. ${ }^{2}$ The external surface of the body shows mental foramen, and the inner surface of the ramus shows mandibular foramen. The bony canal extending between these two foramina is named a mandibular canal running downward and forward in the body. The inferior alveolar vessels and nerves enter through the Mandibular Foramen, and then it traverses the mandibular canal. Here it gives branches to all lower teeth and finally exits through the mental foramen as mental nerve and vessel. ${ }^{3}$ The mandibular foramen portrays a cardinal anatomical landmark for oral maxillofacial surgeons in the repositioning of the mandible during sagittal split osteotomies performed to correct structural deformities like prognathism and retrognathia. ${ }^{4}$ Furthermore, these landmarks are crucial for adequate anaesthesia in dentistry while performing the inferior

Corresponding Author:

Bajpai Prashant Kumar, Lecturer, Department of Community Medicine, UPUMS, Saifai, Etawah, UP, India. Mob: +91-8005055968; E-mail: prashantbajpaillrm@gmail.com

ISSN: 2231-2196 (Print) ISSN: 0975-5241 (Online)

Received: $06.02 .2021 \quad$ Revised: 12.04 .2021

Accepted: 11.05.2021

Published: 11.10 .2021 
alveolar nerve block (IANB). ${ }^{5}$ There is a stoppage of nerve conduction from inferior alveolar nerves and their branches after local anaesthetic agents' infiltration. Anatomical variations of the mandible and insufficient insertion depth into the soft tissue are assumed to be the critical factors for an unsuccessful nerve block. ${ }^{6}$ The mental foramen is another important landmark in carrying out invasive procedures like a mental or incisive nerve block. ${ }^{7}$ The racial differences, age and sex variations are well observed concerning foramen's shape and position. ${ }^{8}$ The foramen's accurate location and the possibility of a mesial position of an anterior loop of the mental nerve to the mental foramen should be meticulously evaluated before implant surgery to avoid mental nerve injury. ${ }^{9}$ The oedema of the epineurium because of improper placement of the dental implant may involve the mental branch, leading to neurosensory disturbances. ${ }^{10}$ Some studies assumed that the mandibular incisive canal's large diameter might be a basis of implant failure and neurosensory dysfunction. The collection of soft tissue around the implant impairs the osseointegration and leads to implant failure. ${ }^{11}$ Malpositioning of endosseous implants may compromise the anatomical structures and can affect the sensory supply in the distribution of the mental nerve. ${ }^{12}$ The facial trauma caused by road traffic accidents is usually prevalent among young males aged between 16 and 30 years. ${ }^{13}$ The mandible is the second most common facial fracture site after the nasal bones and represents up to $70 \%$ of all facial fractures..$^{14}$ Mandibular fracture is managed more frequently by the open reduction internal fixation (ORIF) method. In scheduling an ORIF, the detailed anatomy that occupies "danger spaces" in the mandible should be considered carefully. Care should be taken while plating between the tooth root apices and the mandibular canal, which holds the inferior alveolar nerve. Miniplates and monocortical screws typically are used in this area. In the mental foramen area, isolation and shielding of the mental nerve are essential before placing the plates. A fracture line crossing the inferior alveolar canal can cause a neurosensory disturbance, and the risk is much greater when the displacement exceeds $5 \mathrm{~mm} .{ }^{15}$ Oral and maxillofacial surgeons must have extensive knowledge of mandibular anatomy, function, and occlusion - all of which are essential elements of diagnosis, treatment planning, and successful patient outcome. Extensive knowledge about variability in the position of these critical anatomical landmarks in different populations is required to avoid complications related to mandibular anaesthesia. For these reasons, the objectives of the present study were to observe the shape, position and distance from various mandibular anatomical landmarks of the mental foramen. We also measure the length of the mandibular canal.

\section{MATERIAL AND METHODS}

\section{Study type and place}

This cross-sectional study was done in the Department of Anatomy in the Medical College of Uttar Pradesh.

\section{Inclusion and exclusion criteria}

The mandibles not showing any deformity apparently, were included in the study. Mandibles of children and the elderly were excluded from the study.

\section{Sample}

A total of 41 human mandibles were available in the department. we applied the census method to recruit the human mandibles in the study. After applying the inclusion and exclusion criteria, thirty dried adult human mandibles with an intact alveolar margin of unknown gender were used in the present study.[Figure 1].

\section{Study duration}

The total duration of the study was six months.

Methodology: The shape of the mental foramen, its relation to the lower teeth and its location were recorded on both sides of the mandible by using digital Vernier callipers. The shape of mental foramen was categorized as oval or circular. [Figure 2A, 2B and 3]. The distance of mental foramen was measured concerning various parts of mandibleL1- Distance of mental foramen from symphysis menti, L2- Distance of mental foramen from the alveolar crest, L3- Distance of mental foramen from the lower border of the body of mandible, L4- Distance of mental foramen from the posterior border of the ramus [Figure 4]. The mandibular canal length was also measured by marking two points perpendicular to mandibular foramen and mental foramen, respectively, and then measuring the distance between these two points. Parameters were measured by using a standard horizontal plane defined by Morront. It says that the mandible when placed on a horizontal surface, the lower border of mandible comes into the highest connection when vertical pressure is used to the second molar teeth. ${ }^{16}$

\section{Statistical analysis}

All the data were first entered in Microsoft Excel 2016 and then statistically analyzed using SPSS version 24.0 (SPSS Inc., Chicago, USA). Frequency data were presented as numbers and percentages. The means were compared using Student's t-test. A p-value less than 0.05 was considered to be statistically significant.

\section{RESULTS}

The shape of mental foramen was found oval in 80 per cent and circular in 20 per cent of the mandible irrespective of side [Table 1]. In the majority of the mandible, the Mental foramen was found 'below the second premolar' both on the right side (73.33 per cent) and the left side ( 66.67 per cent). The second common position of mental foramen on both right and left sides was between premolars (16.67 and 23.33 per cent, respectively) [Table 2]. 
The mean distance of mental foramen from symphysis menti, posterior border of the ramus, alveolar crest, and lower border of the body of mandible was found $24.38 \pm 1.91 \mathrm{~mm}$, $63.62 \pm 2.5 \mathrm{~mm}, 13.15 \pm 1.64 \mathrm{~mm}$, and $14.15 \pm 1.58 \mathrm{~mm}$ on the right side. Whereas on the left side mean distance was $24.01 \pm 1.86 \mathrm{~mm}, 63.49 \pm 2.22 \mathrm{~mm}, 13.23 \pm 1.65 \mathrm{~mm}$, and $14.06 \pm 1.69 \mathrm{~mm}$, respectively, from the above parameters. [Table 3]The mean length of the mandibular canal on the right and left sides were $52.34 \pm 2.67$ and $52 . \pm 2.35$ respectively. There was no significant difference between the length of the right and left mandibular canal [Table 4].

\section{DISCUSSION}

The most common location of mental foramen concerning lower teeth was below the second molar on both sides. Similar results were reported by Parmar $2013(64.7 \%$ rt. and $66.7 \%$ lt.), Siddiqui et al. (2011) and Udhaya K.et al. (2013). ${ }^{17,18,19}$ Discordant to the present study, Gingor et al. (in 2006) reported that the location of mental foramen was between premolars in $71.5 \%$ and $22.44 \%$ lies below the second molar. ${ }^{20}$ In the present study on rt. side it was $73.33 \%$ rt. and $66.67 \%$, which was discordant to the study done by Parmar et al., Siddiqui et al., and Udhaya K. et al. where it was lying more on the left side. ${ }^{17,18,19}$ In the present study the most common shape of mental foramen was oval $(80 \%)$ which is almost similar to study by Siddiquiet al. (2011), Western India on 93 mandible $70 \%$ oval and $30 \%$ circular mental foramen, Udhaya K.et al. (2013), South India $(n=90) 75(83.3 \%)$ oval, $15(16.7 \%)$ rounded, Fabian2007, Tanzania $(\mathrm{n}=100)$ oval 54(54.0\%), rounded 46(46.0\%), and Prabodha 2006, Sri Lanka ( $\mathrm{n}=24)$ 16(66.7\%) oval, 8(33.3\%) rounded. ${ }^{18,19,21,22}$ The mean distance of mental foramen in mm from Symphysis Menti, Posterior Border of the ramus, Alveolar Crest, and lower border of the body of mandible was 24.21, 63.56, 13.19, and 14.11, respectively. These findings were similar to the study done separately by Udhaya K. et al., Prabodha et al., and Singh et al. ${ }^{19,21,23}$ The mean Length of the Mandibular Canal was $52.17 \mathrm{~mm}$ with SD 2.49 .

\section{CONCLUSION}

The present study reveals that the most common shape of mental foramen is, oval similar to the population of Western Indians, South Indians, Tanzania, and Sri Lanka. Its usual position was below the second premolar. Since it is not possible to palpate the MF clinically, it is necessary to know its accurate place. This will reduce the chances of inadvertent injury during invasive dental procedures like various preprosthetic operations and implant insertion. The knowledge of the mandibular canal's anatomic configuration will also reduce the damage during Osteotomies and placement of endosseous implant surgery. The present study also measured the mandibular canal length that can be correlated with CT related studies of inferior alveolar nerve and vessels.

\section{Limitations}

As the study was done on a small sample size and mandibles in a college of Uttar Pradesh, the results cannot be generalized for the whole population. So, there is a need for studies with larger sample sizes and different geographical areas for the general application of the results.

\section{ACKNOWLEDGEMENT}

Authors acknowledge the immense help received from the Staff of the Anatomy department and authors whose articles are cited and included in references of this manuscript.

\section{Source of Funding: Nil}

\section{Conflict of Interest: None Declared}

Authors' Contribution: All authors have contributed equally in study design, methodology, data analysis, and writing the manuscript.

\section{REFERENCES}

1. Saladin K, Homan J. Student study guide for use with Anatomy and Physiology. 3rd edBoston: McGraw-Hill;2003, pp.259-60.

2. Breeland G, Aktar A, Patel BC. Anatomy, Head and Neck, Mandible. [Updated 2020 Aug 10]. In: StatPearls [Internet]. Treasure Island (FL): StatPearls Publishing; 2020 Jan-. Available from: https://www.ncbi.nlm.nih.gov/books/NBK532292/

3. Standring S, Ellis H, Healy J C, Johnson D, Williams A, Collins P, et al. Grays Anatomy. 39 th ed. Elsevier: Churchill Livingstone, London; 2005. p. 482.

4. Heasman PA. Variation in the position of the inferior dental canal and its significance to restorative dentistry. J Dent 1988;16:36-9

5. Bremer G. Measurements of special significance in connection with anaesthesia of the inferior alveolar nerve. Oral Surg Oral Med Oral Pathol1952;5:966-88

6. Thangavelu K, Kannan R, Kumar NS, Rethish E, Sabitha S, Sayeeganesh N. Significance of localization of mandibular foramen in an inferior alveolar nerve block. J Nat Sci Biol Med. 2012;3:156-60.

7. Betz D, Fane K. Mental Nerve Block. [Updated 2020 Aug 16]. In: StatPearls [Internet]. Treasure Island (FL): StatPearls Publishing; 2020 Jan-. Available from: https://www.ncbi.nlm.nih. gov/books/NBK482243/

8. Green RM. The position of the mental foramen: a comparison between the southern (Hong Kong) Chinese and other ethnic and racial groups. Oral Surgery, Oral Medicine, Oral Pathology. 1987 Mar 1;63(3):287-90

9. Greenstein G, Tarnow D. The mental foramen and nerve: clinical and anatomical factors related to dental implant placement: a literature review. J Periodontol. 2006 Dec;77(12):1933-43. doi: 10.1902/jop.2006.060197. PMID: 17209776

10. Parnia F, Moslehifard E, Hafezeqoran A, Mahboub F, MojaverKahnamoui H. Characteristics of anatomical landmarks in the 
mandibular interforaminal region: a cone-beam computed tomography study. Medicina Oral, Patologia Oral y CirugiaBucal. 2012 May;17(3):e420-5. DOI: 10.4317/medoral.17520.

11. Rosenquist B. Is there an anterior loop of the inferior alveolar nerve? Int J Periodontics Restorative Dent. 1996;16:40-5.

12. Wismeijer D, van Waas MA, Vermeeren JI, Kalk W. Patients' perception of sensory disturbances of the mental nerve before and after implant surgery: a prospective study of 110 patients. $\mathrm{Br}$ J Oral Maxillofac Surg. 1997;35:254-9.

13. Haug RH, Prather J, Indresano AT. An epidemiologic survey of facial fractures and concomitant injuries. J Oral Maxillofac Surg. 1990 Sep;48(9):926-32. doi: 10.1016/0278-2391(90)90004-1. PMID: 2395044

14. Laub DR. Mandibular Fractures. Medscape. 2016 Jan 14. Available online: http://emedicine.medscape.com/ article/1283150overview\#a4

15. Dreizin, D., Nam, A. J., Tirada, N., Levin, M. D., Stein, D. M., Bodanapally, U. K., et al. Multidetector CT of mandibular fractures, reductions, and complications: A clinically relevant primer for the radiologist. Radiogr. 2016; 36(5), 1539-1564. https:// doi.org/10.1148/rg.2016150218

16. Santini, A., Alayan, I. A comparative anthropometric study of the position of the mental foramen in three populations. Br Dent J. 212, E7 (2012). https://doi.org/10.1038/sj.bdj.2012.143
17. Parmar A, Shah K, Patel B, Jadav J, Trivedi B, Kothari G. Morphological and Morphometric analysis of mental foramen in dry human mandibles. Int J Med Sci Public Health. 2013;2(3):654.

18. Siddiqui A, Daimi S, Mishra P, Doshi S, Date J et al. Morphological and morphometric analysis of mental foramen utilizing various assessment parameters in dry human mandibles. Int J Stud Res. 2011;1(1):19-22.

19. Udhaya K, Saraladevi KV, Sridhar J. The morphometric analysis of the mental foramen in adult dry human mandibles: A study on the South Indian population. J Clin Diagn Res. 2013;7:1547-51

20. Gingor K, Ozturk M, Semiz M, Brooks SL. A radiographic study of the location of mental foramen in a selected Turkish population on panoramic radiograph. Coll Antropol. 2006;30(4):801-5

21. Fabian FM. Position, shape and direction of opening of mental foramen in dry mandibles of Tanzanian adult black males. Ital J AnatEmbryol. 2007;112(3):169-77.

22. Prabodha LBL, Nanayakkara BG. The position, dimensions and morphological variations of mental foramen in mandibles. Galle Med J. 2006;11(1):13-5

23. Singh SK, Gopinath K, Dhall U, Chhabra S. Variation in the position and number of mental foramen in mandibles of North Indian population. J Anat Soc India. 1992;41(1):47-51.

Table 1: Distribution of mandibles according to the shape of Mental Foramen

\begin{tabular}{lcccc} 
Shape & \multicolumn{2}{c}{ Side } & \multicolumn{2}{c}{ Left } \\
& Number & Right & Nercent(\%) & Percent (\%) \\
Oval & 24 & 80.00 & 24 & 80.00 \\
Circular & 6 & 20.00 & 6 & 20.00 \\
Total & 30 & 100.00 & 30 & 100.00 \\
\hline
\end{tabular}

Table 2: Location and Relation of Mental Foramen with Lower Teeth

\begin{tabular}{lcccccccc} 
Side & \multicolumn{2}{c}{ Between Premolars } & \multicolumn{2}{c}{ Below Second Premolar } & \multicolumn{2}{c}{ Below First Molar } & \multicolumn{2}{c}{ Total } \\
& No. & $\%$ & No. & $\%$ & No. & $\%$ & No. & $\%$ \\
Right & 5 & 16.67 & 22 & 73.33 & 3 & 10.00 & 30 & 100.00 \\
Left & 7 & 23.33 & 20 & 66.67 & 3 & 10.00 & 30 & 100.00 \\
\hline
\end{tabular}

Table 3: Location of mental foramen:

\begin{tabular}{|c|c|c|c|c|c|}
\hline \multicolumn{2}{|l|}{ Side } & $\begin{array}{l}\text { Distance from } \\
\text { Symphysis Menti }\end{array}$ & $\begin{array}{l}\text { Distance from } \\
\text { Posterior Border }\end{array}$ & $\begin{array}{l}\text { Distance from } \\
\text { Alveolar Crest }\end{array}$ & $\begin{array}{l}\text { Distance from the lower border } \\
\text { of the body of the mandible }\end{array}$ \\
\hline \multirow[t]{2}{*}{ Right } & Mean & 24.38 & 63.62 & 13.15 & 14.15 \\
\hline & SD & 1.91 & 2.57 & 1.64 & 1.58 \\
\hline \multirow[t]{2}{*}{ Left } & Mean & 24.01 & 63.49 & 13.23 & 14.06 \\
\hline & SD & 1.86 & 2.22 & 1.65 & 1.69 \\
\hline \multirow[t]{2}{*}{ Total } & Mean & 24.21 & 63.56 & 13.19 & 14.11 \\
\hline & SD & 1.88 & 2.38 & 1.63 & 1.62 \\
\hline
\end{tabular}


Table 4: Length of mandibular canal.

\begin{tabular}{lcccc} 
& \multicolumn{4}{c}{ Length of Mandibular canal (in millimetres) } \\
& Mean & SD & T & Sig. (2 tailed) \\
Right Side & 52.34 & 2.67 & 0.529 & 0.599 \\
Left Side & 52.00 & 2.35 & & \\
Overall (Both Side) & 52.17 & & 2.49 & \\
\hline
\end{tabular}

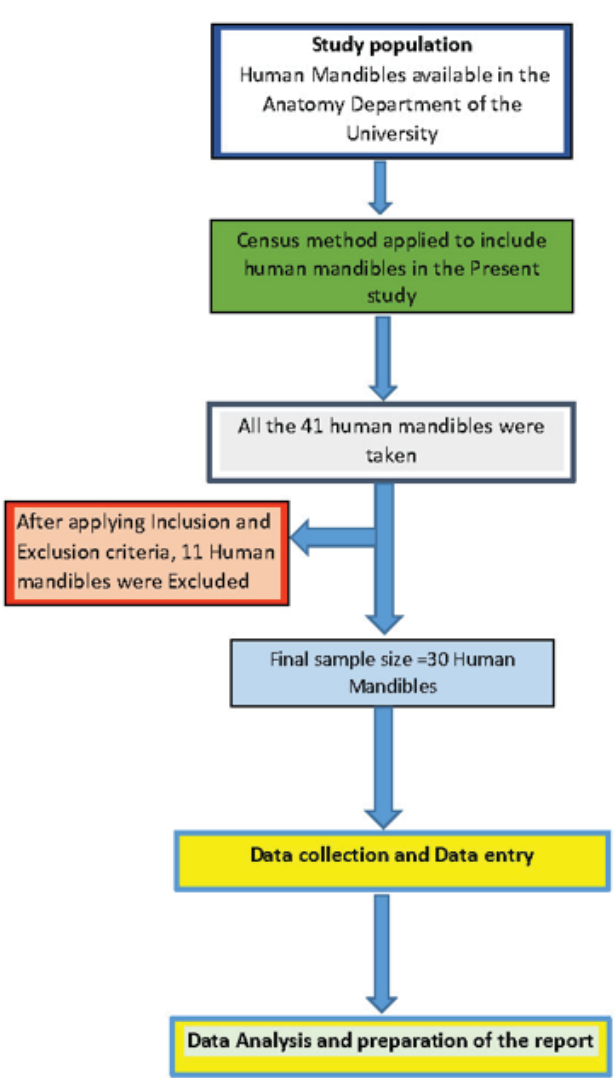

Figure 1: Study Flow Diagram.

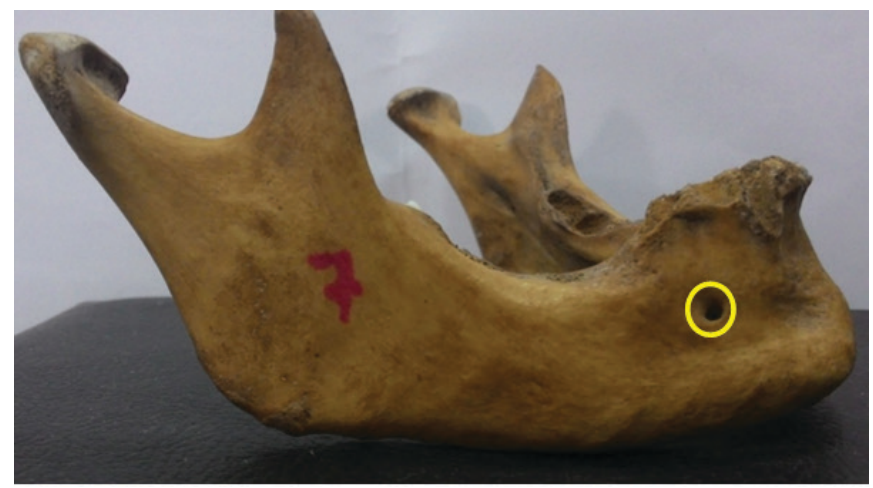

Figure 2A: Photograph showing shape of mental foramen: circular shape (inside yellow marked area).

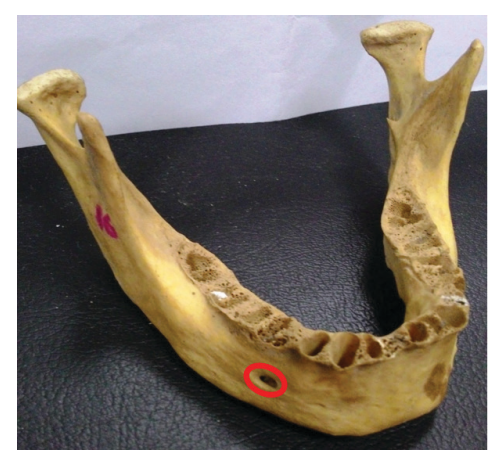

Figure 2B: Photograph showing shape of mental foramen: oval shape (inside red marked area).

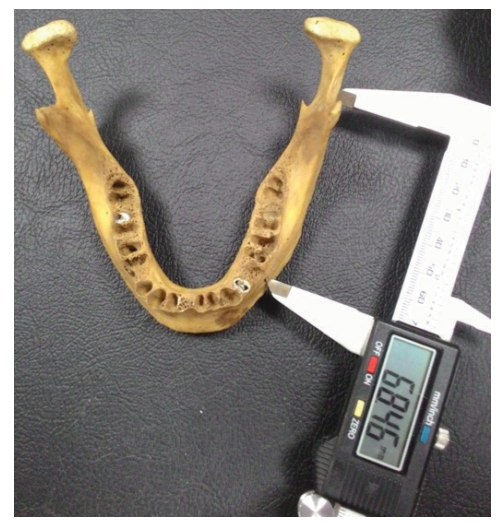

Figure 3: Measuring position of mental foramen.

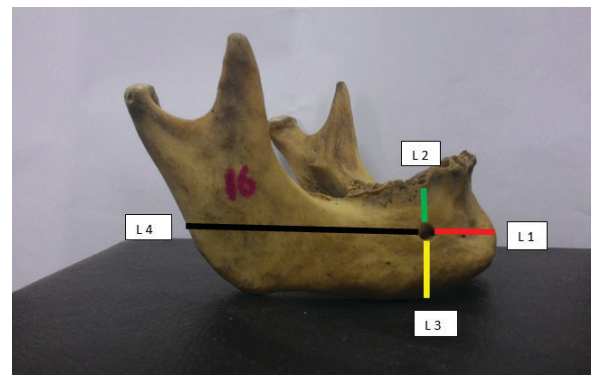

Figure 4: Distance of mental foramen from symphysis menti, alveolar crest, lower border of the body of the mandible and from the posterior border of ramus such that; L1- Distance of mental foramen from symphysis menti (red), L2- Distance of mental foramen from alveolar crest (green), L3- Distance of mental foramen from the lower border of the body of the mandible (yellow), L4- Distance of mental foramen from the posterior border of the ramus (black). 